\title{
Global and local interactions in the structure of crystalline 7-(diethylamino)-2-(2-oxo-2H-chromen-3-yl)chromenium perchlorate
}

\author{
Beata Zadykowicz ${ }^{1} \cdot$ Michał Wera $^{1} \cdot$ Edward V. Sanin $^{2} \cdot$ Alexander I. Novikov $^{2}$ • \\ Alexander D. Roshal ${ }^{2} \cdot$ Artur Sikorski $^{1} \cdot$ Piotr Storoniak $^{1} \cdot$ Jerzy Błażejowski $^{1}$
}

Received: 20 February 2015/ Accepted: 28 April 2015/Published online: 9 May 2015

(c) The Author(s) 2015. This article is published with open access at Springerlink.com

\begin{abstract}
Computational methods were used to calculate the crystal lattice energy reflecting global interactions, predominantly long-range electrostatic interactions between ions, as well as the energy of selected specific local $\mathrm{C}-\mathrm{H} \cdots \mathrm{O}$, $\mathrm{C}-\mathrm{H} \cdots \pi$ and $\pi \cdots \pi$ interactions found in synthesized 7-(diethylamino)-2-(2-oxo-2H-chromen-3-yl)chromenium perchlorate, the structure of which was determined by X-ray crystallography. Local interactions occurring between specific sites of molecules, amounting to a few tens of $\mathrm{kJ} \mathrm{mol}^{-1}$, most likely account for the mutual arrangement of molecular ions, whereas global ones, exceeding half-athousand $\mathrm{kJ} \mathrm{mol}^{-1}$, are responsible for the thermodynamic stability of the compound investigated in the crystalline solid phase, whose potential applications are briefly outlined.
\end{abstract}

Keywords 2-(Coumarinyl)chromenium salt - Crystal engineering and structure . Thermodynamics and features of global and local interactions - Spectral properties

Electronic supplementary material The online version of this article (doi:10.1007/s11224-015-0596-6) contains supplementary material, which is available to authorized users.

Jerzy Błażejowski

jerzy.blazejowski@ug.edu.pl

1 Faculty of Chemistry, University of Gdańsk, Wita Stwosza 63, 80-308 Gdańsk, Poland

2 Institute of Chemistry, V. N. Karazin National University, Svobody 4, Kharkiv 61077, Ukraine

\section{Introduction}

Thermodynamic forces leading to the formation of crystalline solids are interactions between basic chemical entities such as atoms, molecules, ions or molecular ions. Knowledge of such interactions is thus crucial for understanding crystallization phenomena and the secrets of crystal engineering. Non-specific interactions between chemical entities are common in any crystalline solid. In ionic solids, however, long-range electrostatic interactions also occur, which substantially stabilize the crystal lattice. Determining the energy of both these interactions, henceforth referred to as global interactions, as well as the energy of local interactions occurring between specific sites of molecules, thus provides an opportunity to assess the extent to which they contribute to the formation and stabilization of crystalline solid phases. This is the important issue that we are addressing in this work.

The compound used in our explorations of these various types of interactions was crystalline 7-(diethylamino)-2-(2oxo- $2 \mathrm{H}$-chromen-3-yl)chromenium perchlorate (1). We synthesized this molecular ionic substance in view of the widespread occurrence of $2 \mathrm{H}$-chromen-2-one (coumarin) derivatives in living matter [1] and their interesting spectral features [2,3], which can be put to use in analytics [4, 5]. By combining coumarin and chromenium moieties of wellknown absorption and fluorescent abilities [3, 6-8] in one molecule and supplementing the latter moiety with a medium-sensitive amino group, we expected to obtain an efficient spectral probe of the acidic/basic or electrophilic/ nucleophilic properties of an environment.

This paper reports briefly on the synthesis, identification and crystal structure determination of $\mathbf{1}$. Furthermore, intra- and intermolecular interactions within the crystal (such as $\mathrm{C}-\mathrm{H} \cdots \mathrm{O}$, [9] $\mathrm{C}-\mathrm{H} \cdots \pi[10,11]$ and $\pi \cdots \pi[12-14])$ are 
localized and described. Calculations were then performed to find out how the energy and Gibbs free energy of the isolated cation of $\mathbf{1}$ changes during the rotation of chromenium relative to $2 \mathrm{H}$-chromen-2-one and diethylamino relative to chromenium fragments and whether its structure in the crystalline solid phase corresponds to the lowest energy one. The energies and Gibbs free energies of intramolecular and selected intermolecular interactions within the isolated cation and the molecular assemblies revealed in crystalline 1 were calculated and used to explore how far they contribute to crystal packing. Next, the Gibbs free energy changes (relevant to the formation of selected molecular assemblies revealed in crystalline 1) in several liquid phases were calculated in order to obtain some idea of how the medium affects the compound's crystallization. Then, the energy and entropy contributions to the Gibbs free energy of crystalline 1 were evaluated so as to get an idea of the extent to which they influence the compound's thermodynamic stability. Finally, preliminary investigations of the spectral features of $\mathbf{1}$, important from the point of view of its potential applications, were undertaken.

\section{Materials and methods}

\section{Synthesis}

Compound (1) was synthesized using a modified version of the procedure described in the literature [15]. A mixture of 4-(diethylamino)-2-hydroxybenzaldehyde and 3-acetyl$2 \mathrm{H}$-chromen-2-one in glacial acetic acid was stirred until complete dissolution of the latter compound. Then, a $65 \%$ solution of perchloric acid in water was added and the reactant mixture boiled for $1 / 2 \mathrm{~h}$. After cooling, a small portion of diethyl ether was added; this caused the product to precipitate. The identity of the compound was confirmed from the MS $\left[\mathrm{m} / \mathrm{z}=346\left[\mathrm{M}^{+}\right]\right.$(FAB) $]$and ${ }^{1} \mathrm{H}$ NMR spectra (Table 1S in the Supplementary data) of the cation of 1 (Fig. 1). Dark red crystals suitable for X-ray investigations were grown from propan-2-ol/acetonitrile $(4 / 1 \mathrm{v} / \mathrm{v})$ solution (m.p. 502-503 K).

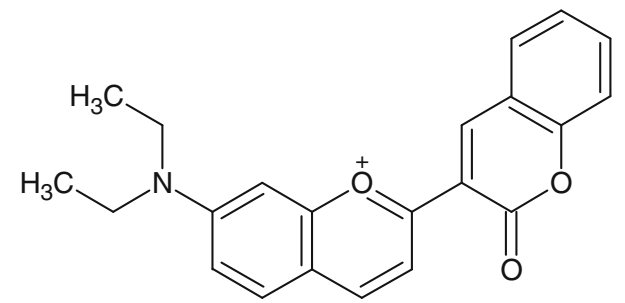

Fig. 1 Canonical structure of the cation of 1

\section{X-ray crystallography}

Crystallographic data were collected on an Oxford Diffraction Gemini R Ultra Ruby CCD diffractometer with graphite-monochromatic Mo-K $\alpha$ radiation $(\lambda=0.71073 \AA)$ at $295 \mathrm{~K}$. Crystal data and details concerning the structural refinement are given in the Supplementary data, Tables $2 \mathrm{~S}$ and 3 S and CCDC 916451.

ORTEP-3 [16] software was used to prepare the molecular graphics, and the PLATON [17] and CrystalExplorer [18] programs to reveal and analyse the molecular interactions.

\section{Spectroscopic measurements}

The liquid and solid state absorption spectra were recorded on a Hitachi U3210 spectrophotometer.

Doubly distilled water and spectral grade solvents were used throughout. Analar grade $\mathrm{NaOH}$ and $\mathrm{HCl}$ were used to record spectra in alkalinated or acidified water media, respectively.

\section{Computations}

Unconstrained geometry optimizations were carried out applying the Gaussian09 program package [19], either at the density functional theory (DFT) [20], dispersion-corrected density functional theory (DFT-D) [21] (in selected cases) or TD (time dependent) DFT [22] levels with the B3LYP functional [23-25] using gradient techniques [26] and the 6-31G** basis set [27] or, in selected cases, at the MP2 level [28] using the cc-pVDZ basis set [29, 30] with and without (gaseous phase) the influence of the solvent; in the former case, the polarized continuum model (PCM) was applied (UHF radii were used to obtain the molecular cavity) [31, 32]. Harmonic vibrational frequencies (Hessian matrix) were computed to verify whether the optimized structures correspond to true stationary (minima or transition) states [27] and used to predict the zero-point energy, thermal energy (enthalpy) and entropy of gaseous entities [33]. ${ }^{1} \mathrm{H}$ magnetic shielding tensors were obtained following the gauge-including atomic orbital (GIAO) approach [34-36].

The energies of long-range electrostatic and short-range non-specific dispersive and repulsive contributions to the crystal lattice energy (calculated by combining the Coulomb and Buckingham equations), representing the energy of global interactions (occurring between many molecular ions and any adjacent atoms of such neighbouring ions (Fig. 1S in the Supplementary data)), were obtained using the General Utility Lattice Program (GULP) [37]. It was assumed that the relative charges of cations and anions were +1 and -1 , respectively, and that the relative atomic 
partial charges necessary for calculating the energy of electrostatic interactions were those reproducing the molecular electrostatic potential (MEP) around these entities [38] at the level of the M062X [39, 40] functional and $6-31++\mathrm{G}^{* *}$ basis set [41]. It was further assumed that the atomic parameters for calculating the energy of dispersive and repulsive pairwise interactions were those reported in the literature [42, 43].

\section{Results and discussion}

\section{Crystal structure of 1 in the context of the mutual arrangement of ions and local and global interactions}

The bond lengths (Table $3 \mathrm{~S}$ in the Supplementary data), similar to those reported for the compounds containing chromenium [44, 45] and $2 H$-chromen-2-one [46, 47] moieties, confirm the molecular structure of $\mathbf{1}$.

The cation of $\mathbf{1}$ links the nearly planar chromenium and $2 \mathrm{H}$-chromen-2-one moieties, which are twisted with respect to each other through an angle of $7.1(2)^{\circ}$ in the crystalline solid phase (Table $4 \mathrm{~S}$ in the Supplementary data). The almost planar 2-(2-oxo-2H-chromen-3yl)chromenium core may be a consequence of the appearance of two intramolecular $\mathrm{C}-\mathrm{H} \cdots \mathrm{O}$ interactions (Fig. 2), whose contribution to the structural stabilization of the cation of $\mathbf{1}$ will be considered in due course. The diethylamino group in the cation of $\mathbf{1}$ is almost planar within the C7/N21/C23/C24 atoms and coplanar with the chromenium skeleton (Table $4 \mathrm{~S}$ in the Supplementary data).

The tetrahedral perchlorate anions, the counterparts of the cations described above, occupy two positions in the crystalline solid phase of $\mathbf{1}$, with occupancy factors of $0.764(10)$ and $0.236(10)$ for $\mathrm{Cl} 27 / \mathrm{O} 28-\mathrm{O} 31$ and $\mathrm{Cl} 27 \mathrm{~A} /$
O28A-O31A, respectively (Fig. 2). This feature of the anion is not unique, since such disordered species have been found by ourselves [48] and others [49, 50].

The structural analysis revealed various types of intraand intermolecular interactions in the crystal lattice of $\mathbf{1}$, considered subsequently as specific local interactions: these are listed in Tables 1, 2, 3 and illustrated in Figs. 3 and 4 . The cations and anions, linked via three $\mathrm{Cl}-\mathrm{O} \cdots \pi$ contacts, are assembled in ion pairs. Inversely oriented ion pairs are arranged in corrugated layers in the ac plane (Fig. 5) in which cations are in contact via $\mathrm{C}-\mathrm{H} \cdots \pi$ and $\pi \cdots \pi$ interactions, and cations and anions via $\mathrm{C}-\mathrm{H} \cdots \mathrm{O}(\mathrm{Cl})$ interactions. Inversely interrelated layers are in contact via $\mathrm{C}-\mathrm{H} \cdots \mathrm{O}(\mathrm{C}, \mathrm{Cl})$ interactions. The network of these specific local interactions, together with long-range electrostatic interactions between ions, predominant in crystalline ionic solids, and common non-specific dispersive and repulsive interactions stabilize the crystal lattice of $\mathbf{1}$, whose subtle column architecture is depicted in Fig. $2 \mathrm{~S}$ in the Supplementary data.

Thorough analysis of Hirshfeld surfaces (Figs. 6 and 3S in the Supplementary data) and the associated fingerprint plots [51-57] (Figs. 7 and 4S in the Supplementary data) obtained using the CrystalExplorer program [18], carried out in accordance with the rules outlined in the literature and the examples described [51-57], confirms the occurrence of the interactions which are listed in Tables 1,2 and 3. All the anions in the vicinity of the cation strongly influence the Hirshfeld surfaces (contribution $35.5 \%$ ) through $\mathrm{C}-\mathrm{H} \cdots \mathrm{O}(\mathrm{C}, \mathrm{Cl})$ interactions (red/yellow spots in Figs. 6 and $3 \mathrm{~S}(\mathrm{~A})$ in the Supplementary data). Conspicuous are the $\mathrm{C}-\mathrm{H} \cdots \pi$ and $\pi \cdots \pi$ interactions involving benzene, and benzene and $2 \mathrm{H}$-pyran-2-one rings, which contribute 15.7 and $10.1 \%$, respectively, to the total Hirshfeld surface (they are reflected by the light blue-yellowish area in Fig. 6, the red and blue triangles in Fig. 3S(C) in the Supplementary data and the flat regions in Fig. 3S(D) in

Fig. 2 Molecular structure of 1 (25\% probability level ellipsoids represent non- $\mathrm{H}$ atoms; small spheres of arbitrary radius represent $\mathrm{H}$ atoms) showing the labelling of atoms, the numbering of aromatic ring centroids ( $\mathrm{Cg} 1-$ Cg4) and $\mathrm{C}-\mathrm{H} \cdots \mathrm{O}$ (dashed lines) interactions

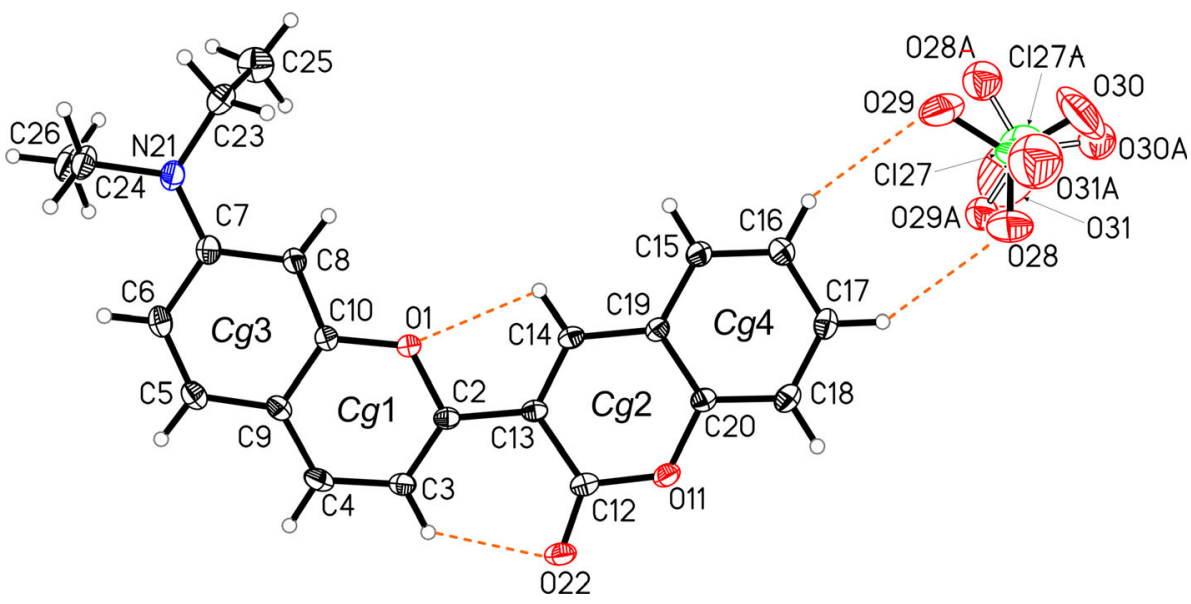


Table 1 Hydrogen-bonding $(\mathrm{C}-\mathrm{H} \cdots \mathrm{O}(\mathrm{C}, \mathrm{Cl}), \mathrm{C}-\mathrm{H} \cdots \pi)$ interactions in $\mathbf{1}$

\begin{tabular}{llllll}
\hline Method & $\mathrm{D}-\mathrm{H} \cdots \mathrm{A}^{\mathrm{a}}$ & $\mathrm{D}-\mathrm{H}(\AA)$ & $\mathrm{H} \cdots \mathrm{A}(\AA)$ & $\mathrm{D} \cdots \mathrm{A}(\AA)$ & $\mathrm{D}-\mathrm{H} \cdots \mathrm{A}\left({ }^{\circ}\right)$ \\
\hline X-ray & $\mathrm{C} 3-\mathrm{H} 3 \cdots \mathrm{O} 22$ & $1.00(5)$ & $2.21(5)$ & $2.863(6)$ & $122(3)$ \\
MP2 & & 1.09 & 2.09 & 2.832 & 123 \\
DFT & & 1.08 & 2.10 & 2.840 & 123 \\
X-ray & $\mathrm{C} 4-\mathrm{H} 4 \cdots \mathrm{O} 22^{\mathrm{i}}$ & $0.99(5)$ & $2.51(5)$ & $3.454(6)$ & $159(3)$ \\
DFT & & 1.09 & 2.58 & 3.287 & 122 \\
X-ray & $\mathrm{C} 14-\mathrm{H} 14 \cdots \mathrm{O} 1$ & $1.02(3)$ & $2.30(3)$ & $2.671(5)$ & $100(2)$ \\
MP2 & & 1.09 & 2.33 & 2.692 & 97 \\
DFT & & 1.08 & 2.34 & 2.698 & 97 \\
X-ray & $\mathrm{C} 14-\mathrm{H} 14 \cdots \mathrm{O} 29^{\mathrm{ii}}$ & $1.03(3)$ & $2.43(3)$ & $3.409(9)$ & $160(3)$ \\
X-ray & $\mathrm{C} 16-\mathrm{H} 16 \cdots \mathrm{O} 29$ & $1.12(5)$ & $2.56(5)$ & $3.499(10)$ & $153(3)$ \\
DFT & & 1.09 & 2.22 & 3.225 & 152 \\
X-ray & $\mathrm{C} 17-\mathrm{H} 17 \cdots \mathrm{O} 28$ & $0.99(5)$ & $2.48(5)$ & $3.362(8)$ & $149(4)$ \\
DFT & & 1.09 & 2.21 & 3.177 & 146 \\
X-ray & $\mathrm{C} 18-\mathrm{H} 18 \cdots \mathrm{O} 30^{\mathrm{iii}}$ & $0.97(5)$ & $2.40(5)$ & $3.181(10)$ & $137(4)$ \\
X-ray & $\mathrm{C} 23-\mathrm{H} 23 \mathrm{~A} \cdots \mathrm{Cg} 3^{\mathrm{iv}}$ & $0.98(5)$ & $3.09(5)$ & $3.552(5)$ & $110(3)$ \\
DFT & & 0.97 & 3.00 & 3.553 & 118 \\
X-ray & $\mathrm{C} 23-\mathrm{H} 23 \mathrm{~B} \cdots \mathrm{O} 31^{\mathrm{ii}}$ & $1.03(6)$ & $2.47(6)$ & $3.416(15)$ & $152(4)$ \\
X-ray & $\mathrm{C} 24-\mathrm{H} 24 \mathrm{~A} \cdots \mathrm{O} 28^{\mathrm{v}}$ & $1.07(5)$ & $2.32(5)$ & $3.366(8)$ & $164(4)$ \\
\hline
\end{tabular}

$\mathrm{Cg} 3$ is the centroid of the C5-C10 ring. Predicted values refer to LE structures in Fig. 8 (intramolecular C$\mathrm{H} \cdots \mathrm{O}(\mathrm{C})$ interactions) and $\mathbf{b}(\mathrm{min}), \mathbf{c}(\mathrm{min})$ and $\mathbf{d}(\mathrm{min})$ structures in Fig. 9 [relevant intermolecular interactions indicated in Fig. 5S (Supplementary data)]

a Symmetry transformations: (i) $-x+1, y+1 / 2,-z+3 / 2$; (ii) $-x+1, y+1 / 2,-z+1 / 2$; (iii) $x,-y+1 / 2, z+1 / 2$; (iv) $-x+2,-y+2,-z+1$; (v) $x+1, y+1, z$
Table $2 \mathrm{Cl}-\mathrm{O} \cdots \pi$ interactions in $\mathbf{1}$

\begin{tabular}{lllll}
\hline Method & $\mathrm{X}-\mathrm{I} \cdots \mathrm{J}^{\mathrm{a}}$ & $\mathrm{I} \cdots \mathrm{J}(\AA)$ & $\mathrm{X} \cdots \mathrm{J}(\AA)$ & $\mathrm{X}-\mathrm{I} \cdots \mathrm{J}\left({ }^{\circ}\right)$ \\
\hline X-ray & $\mathrm{C} 127-\mathrm{O} 28 \cdots C g 1^{\mathrm{vi}}$ & $3.217(7)$ & $4.224(2)$ & $127.8(4)$ \\
X-ray & $\mathrm{C} 27-\mathrm{O} 30 \cdots C g 1^{\mathrm{vi}}$ & $3.936(10)$ & $4.224(2)$ & $92.4(4)$ \\
$\mathrm{X}$-ray & $\mathrm{Cl} 27 \mathrm{~A}-\mathrm{O} 31 \mathrm{~A} \cdots C g 1^{\mathrm{vi}}$ & $2.93(2)$ & $4.26(3)$ & $161(2)$ \\
DFT & & 3.56 & 4.62 & 127 \\
\hline
\end{tabular}

$\mathrm{Cg} 1$ is the centroid of the $\mathrm{O} 1 / \mathrm{C} 2-\mathrm{C} 4 / \mathrm{C} 9 / \mathrm{C} 10$ ring. Predicted values refer to the a $(\mathrm{min})$ structure in Fig. $9[\mathrm{Cl}-\mathrm{O} \cdots \pi$ interactions indicated in Fig. 5S (Supplementary data)]

a Symmetry transformation: (vi) $-x+1,-y+1,-z+1$

the Supplementary data). The contribution of $\mathrm{C} \cdots \mathrm{O}$ contacts to the total Hirshfeld surface, tentatively ascribed to $\mathrm{Cl}-\mathrm{O} \cdots \pi$ contacts, is relatively small $(3.5 \%)$ for interactions between oppositely charged ions. On the other hand, the contribution of $\mathrm{H} \cdots \mathrm{H}$ contacts to the total Hirshfeld surface $(33.5 \%)$, common in organic molecular crystals, is quite high. $\mathrm{C}-\mathrm{H} \cdots \mathrm{O}(\mathrm{C}, \mathrm{Cl}), \mathrm{C}-\mathrm{H} \cdots \pi, \mathrm{Cl}-\mathrm{O} \cdots \pi$ and $\pi \cdots \pi$ interactions are more or less localized, whereas $\mathrm{H} \cdots \mathrm{H}$ contacts are diffused throughout the molecule (Figs. 7 and $4 \mathrm{~S}$ in the Supplementary data).

Knowledge of the contributions of various interactions to the thermodynamic stabilization of the crystal lattice is crucial for understanding the fates of entities following the formation of crystalline solid phases, as well as their mutual arrangement and behaviour in these phases. On account of this, the thermodynamics of the global and local specific interactions shown in Fig. 5S in the Supplementary data in the fragments of the crystal structure extracted from the crystal lattice of $\mathbf{1}$ is considered in the next section.

\section{Thermodynamics of local and global interactions in the crystal lattice of 1 and of the process of its formation}

To obtain information on the structure and stability of various entities and thermodynamics of molecular interactions, quantum chemistry calculations were always carried out at the less time-consuming DFT or DFT-D levels, but in certain cases also at the more advanced and timeconsuming MP2 level. Such an approach enabled the calculations to be completed in a reasonable time with the expected comparability of results obtained on various levels. The extent to which the inclusion of dispersive interactions affects the energetics of $\pi \cdots \pi$ contacts was also verified $[58,59]$.

The first issue to be addressed was the stability of various structural/conformational forms of the cation of $\mathbf{1}$ resulting from the rotation of the chromenium relative to $2 \mathrm{H}$-chromen-2-one moieties or the amino group relative to the chromenium moiety. It emerges from geometry 
Table $3 \pi \cdots \pi$ interactions in $\mathbf{1}$

\begin{tabular}{lllllll}
\hline Method & $\mathrm{I}$ & $\mathrm{J}^{\mathrm{a}}$ & $C g \mathrm{I} \cdots C g \mathrm{~J}(\AA)$ & Dihedral angle $\left(^{\circ}\right)$ & $C g \mathrm{I} \_$Perp $(\AA)$ & $C g \mathrm{~J} \_$Offset $(\AA)$ \\
\hline X-ray & 2 & $3^{\text {vii }}$ & $3.570(2)$ & $5.9(2)$ & $3.485(2)$ & $0.774(2)$ \\
DFT & & & 3.583 & 4.8 & 3.532 & 0.602 \\
X-ray & \multirow{2}{*}{$2^{\text {vii }}$} & $3.570(2)$ & $5.9(2)$ & $3.540(2)$ & $0.462(2)$ \\
DFT & & & 3.625 & 6.7 & 3.598 & 0.442 \\
X-ray & 2 & $4^{\text {vi }}$ & $3.596(3)$ & $0.9(2)$ & $3.389(2)$ & $1.440(2)$ \\
DFT & & & 3.729 & 6.8 & 3.512 & 1.253 \\
X-ray & \multirow{2}{*}{4} & $2^{\text {vi }}$ & $3.596(3)$ & $0.9(2)$ & $3.375(2)$ & $1.241(2)$ \\
DFT & & & 3.574 & 8.3 & 3.409 & 1.073 \\
X-ray & \multirow{2}{*}{4} & $4^{\text {vi }}$ & $3.665(2)$ & $0(2)$ & $3.370(2)$ & $1.440(2)$ \\
DFT & & & 3.778 & 5.8 & 3.399 & 1.649
\end{tabular}

I and $\mathrm{J}$ denote interacting rings. $C g 2, C g 3$ and $C g 4$ are the centroids of the O11/C12-C14/C19/C20;C5-C10 and $\mathrm{C} 15-\mathrm{C} 20$ rings, respectively. $C g \mathrm{I} \cdots C g \mathrm{~J}$ is the distance between ring centroids. The dihedral angle is that between the planes of the rings I and J. $C g \mathrm{I}$-Perp is the perpendicular distance of $C g \mathrm{I}$ from ring J. $C g \mathrm{I} \_$Offset is the distance between $C g \mathrm{I}$ and the perpendicular projection of $C g \mathrm{~J}$ on ring I. Predicted values refer to $\mathbf{e}(\mathrm{min})$ and $\mathbf{f}(\mathrm{min})$ in Fig. $9[\pi \cdots \pi$ interaction indicated in Fig. 5S (Supplementary data)]

a Symmetry transformations: (vi) $-x+1,-y+1,-z+1$; (vii) $-x+1,-y+2,-z+1$

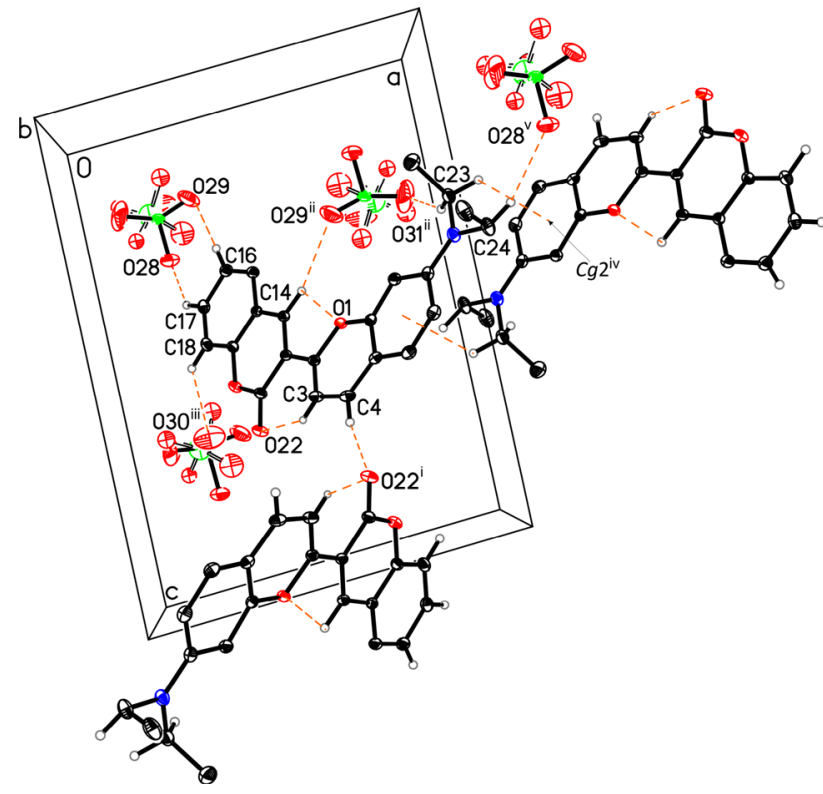

Fig. 3 The arrangement of ions (non-H atoms are represented by $25 \%$ probability level ellipsoids; $\mathrm{H}$ atoms not involved in interactions have been omitted, those involved in interactions are shown as small spheres of arbitrary radius) and $\mathrm{C}-\mathrm{H} \cdots \mathrm{O}$ and $\mathrm{C}-\mathrm{H} \cdots \pi$ interactions (represented by dashed lines) in the crystal lattice of $\mathbf{1}$ (see Table 1 for details)

optimizations at both levels that the lowest energy structure of the cation of $\mathbf{1}$ shown in Figs. 8 and 8S (Supplementary data) is closely related to the structure of this entity in the crystalline solid phase (Tables 3S, 4S in the Supplementary data). However, calculations predict the coplanarity of the chromenium and $2 \mathrm{H}$-chromen-2-one moieties in the gaseous phase and various environments, while in the crystalline solid phase these moieties are twisted by an angle

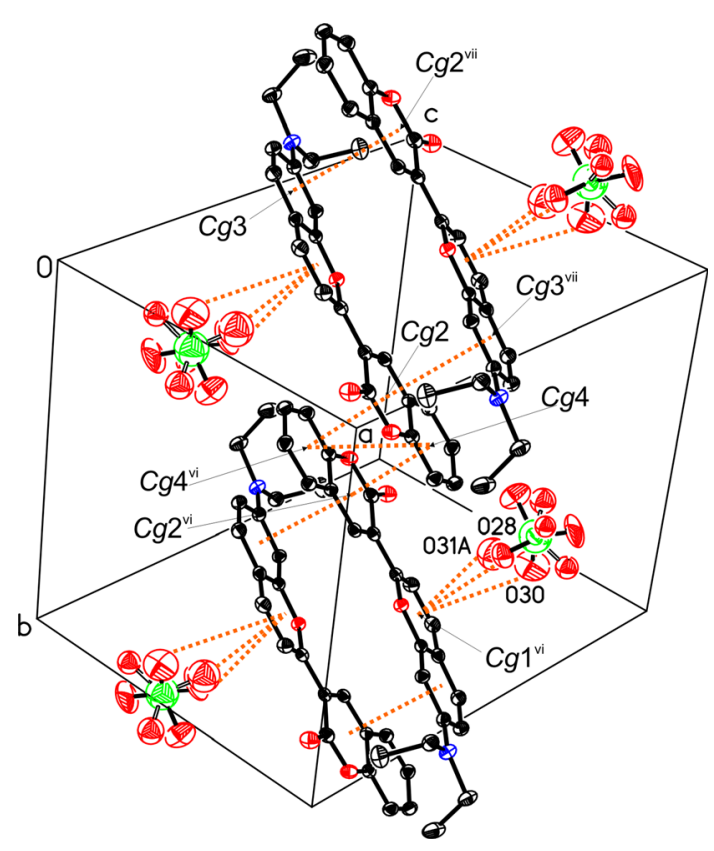

Fig. 4 The arrangement of ions (non- $\mathrm{H}$ atoms are represented by $25 \%$ probability level ellipsoids; $\mathrm{H}$ atoms have been omitted) and $\mathrm{Cl}-\mathrm{O} \cdots \pi$ and $\pi \cdots \pi$ interactions (represented by dotted lines) in the crystal structure of $\mathbf{1}$ (see Tables 2, 3 for details)

exceeding $7^{\circ}$. Further information is provided by two computational experiments.

In the first one, the dihedral angle between the chromenium and $2 \mathrm{H}$-chromen-2-one moieties was changed by $360^{\circ}$, starting from the lowest energy structure. Two transition states and one intermediate state were found on the rotation path (Fig. 8). The energy (Gibbs free energy) of intermediate state, 23.4 (23.6) $\mathrm{kJ} \mathrm{mol}^{-1}$ (MP2 level), 
higher than the lowest energy state represents the structure without $\mathrm{C}-\mathrm{H} \cdots \mathrm{O}$ interactions. This value can thus be tentatively regarded as the sum of the energies (Gibbs free energy) of the two intramolecular H-bonding interactions in the cation of $\mathbf{1}$. Transformation from the lowest energy state to the intermediate state requires energy (Gibbs free energy) activation barriers amounting to 31.5 (32.8)

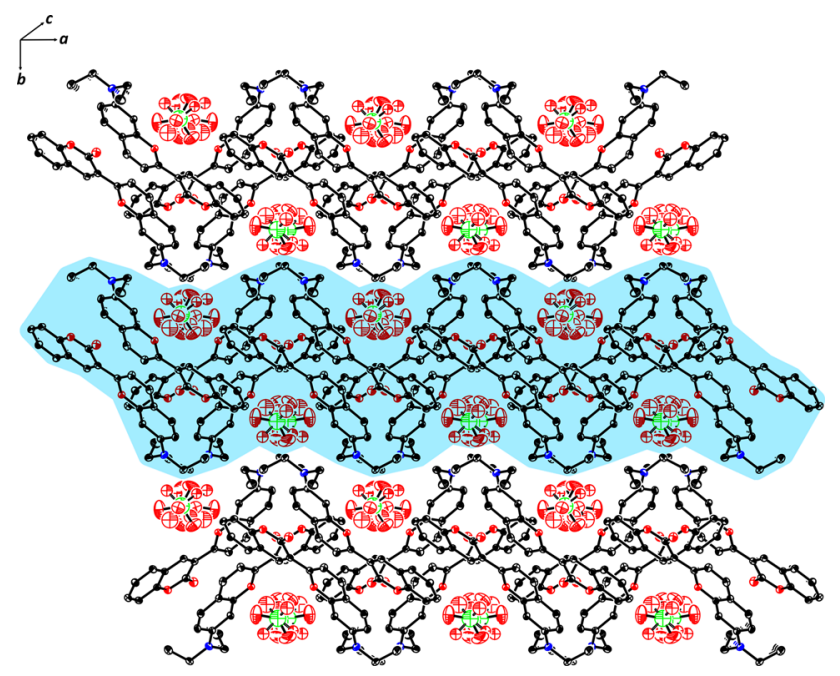

Fig. 5 Projection of the crystal packing ( $\mathrm{H}$ atoms have been omitted; non- $\mathrm{H}$ atoms are represented by $25 \%$ probability level ellipsoids) on the $a b$ plane in $\mathbf{1}$ (interactions are not indicated)
$\mathrm{kJ} \mathrm{mol}^{-1}$ (MP2 level) to be overcome. In the second computational experiment, the dihedral angle between the chromenium moiety and the amino group in the cation of $\mathbf{1}$ was changed by $360^{\circ}$, starting from the lowest energy structure (Fig. 8; Table 4S in the Supplementary data). The results show that rotation by $180^{\circ}$ leads to the lowest energy (Gibbs free energy) state, whereas rotation by ca. $90^{\circ}$ or $270^{\circ}$ leads to transition states with an activation energy (Gibbs free energy) barrier of 65.3 (70.5) or 62.8 (69.7) $\mathrm{kJ} \mathrm{mol}^{-1}$ (MP2 level), respectively (Fig. 6S in the Supplementary data). The results of the above-mentioned calculations thus demonstrate that the lowest energy (Gibbs free energy) structure of the cation of $\mathbf{1}$ can be related to the structure of this entity in the crystalline solid phase. Further, they highlight the importance of intramolecular C$\mathrm{H} \cdots \mathrm{O}$ bonding interactions in the stabilization of the structure of this ion. Finally, it is probable that the almost planar 2-(2-oxo-2H-chromen-3-yl)chromenium core facilitates the appearance of intermolecular $\pi \cdots \pi$ interactions involving chromenium and $2 \mathrm{H}$-chromen-2-one moieties, and consequently the packing of the cations of $\mathbf{1}$ in the crystal.

Selected intermolecular interactions listed in Tables 1, 2 and 3 were considered by carrying out unconstrained geometry optimizations of two-component assemblies of ions in the lowest energy and transition (in the case of cation assemblies) stationary states and isolated ions, starting
Fig. 6 Hirshfeld surface [front (left) and reverse (right) views] of the cation of 1 reflecting the normalized contact distance $\left(d_{\text {norm }}\right)$ with surrounding ions supplemented with selected interactions listed in Tables 1, 2 and 3

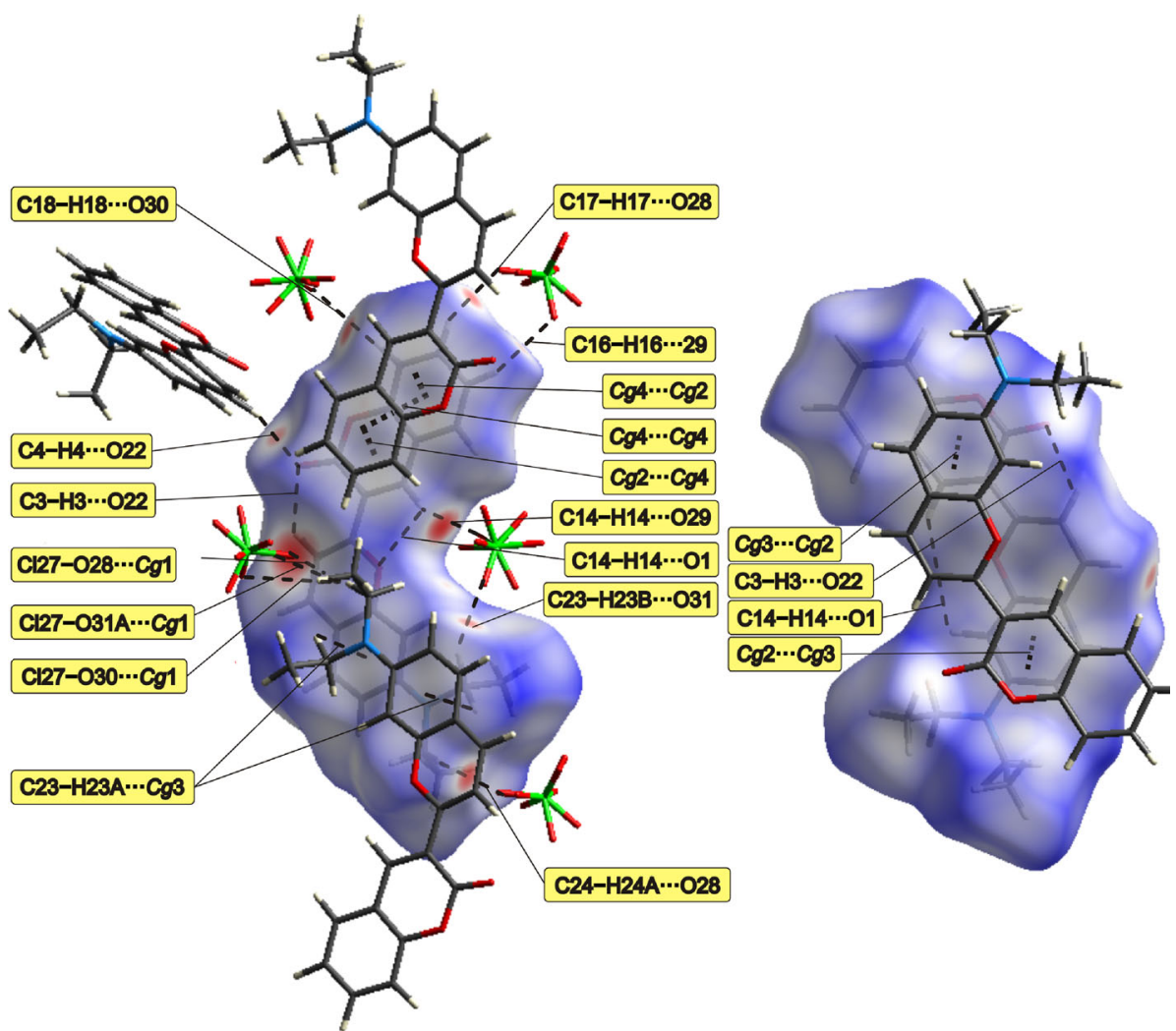



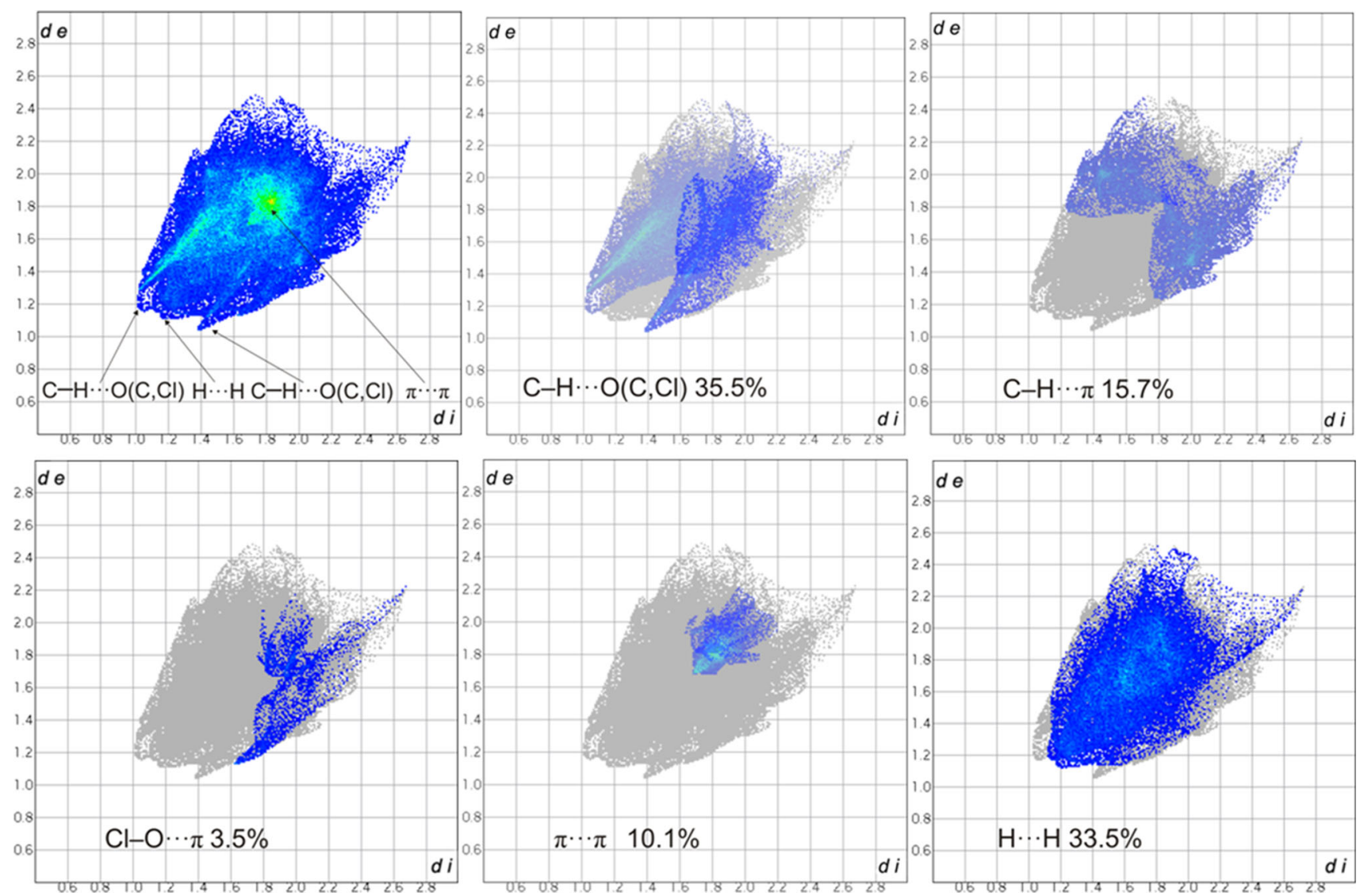

Fig. 7 Two-dimensional $\left(d_{\mathrm{e}} / d_{\mathrm{i}}\right)$ fingerprint plots [full (upper left) and resolved into different interactions—see also Fig. 4S] representing the contributions (in per cent) of particular types of contacts to the total Hirshfeld surface area of the cation of 1

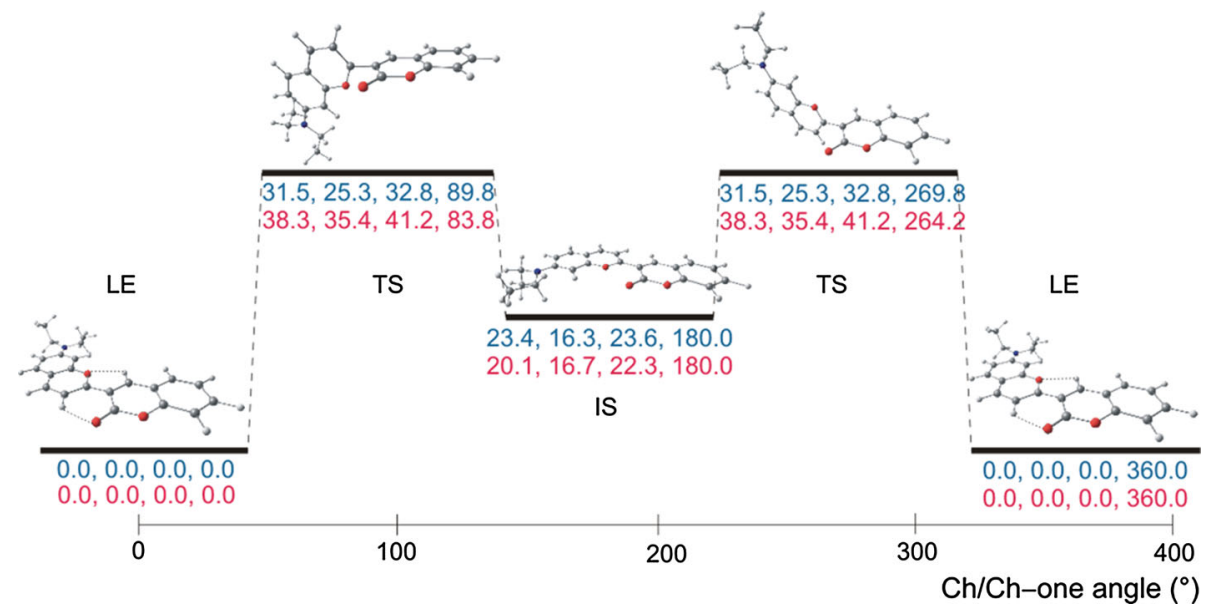

Fig. 8 Structures (MP2/cc-pVDZ level) together with relative values of energy ( $\Delta E$, first value), enthalpy $(\Delta H$, second value), Gibbs free energy $\left(\Delta G\right.$, third value) (in $\mathrm{kJ} \mathrm{mol}^{-1}$ ) and angle (fourth value) representing stationary [lowest energy (LE), intermediate (IS) and

from the relevant structures of these entities in the crystalline solid phase (shown in Fig. 5S in the Supplementary data). Such an approach enabled individual consideration transition (TS) states] points following rotation of chromenium (Ch) relative to $2 \mathrm{H}$-chromen-2-one (Ch-one) moieties (around $\mathrm{C} 2-\mathrm{C} 13$ bond) in the cation of $\mathbf{1}$ predicted at the MP2/cc-pVDZ (blue) and DFT/6-31G** (red) levels (Color figure online)

of all types of intermolecular interactions occurring in crystalline 1 and completion of calculations at the DFT or DFT-D levels within a reasonable time. The optimized 
lowest energy and transition state structures of two-component assemblies of ions together with the relative energies corresponding to their formation from relevant isolated entities are illustrated in Fig. 9, and the thermodynamic data obtained are listed in Table 4. It emerges from the thermodynamic data that only interactions between oppositely charged ions lead to stable ion pairs (a and $\mathbf{c}$ ) in the gaseous and liquid diethyl ether phase (negative values of $\Delta E, \Delta H$ and $\Delta G$ ). When equally charged cations approach one another, there is a gradual increase in energy (Gibbs free energy). On the reaction pathway, however, there are always two stationary points: one corresponding to the energy minimum and the other to the transition state. This means that intermolecular $\mathrm{C}-$ $\mathrm{H} \cdots \mathrm{O}(\mathrm{C})(\mathbf{b}), \mathrm{C}-\mathrm{H} \cdots \pi(\mathbf{d})$ and $\pi \cdots \pi(\mathbf{e})$ interactions occur between equally charged cations, contributing to the local stabilization of the crystal lattice of $\mathbf{1}$. The energy (Gibbs free energy) of these interactions should at least be equal to the difference between the relevant quantities for the transition state and the local minimum. The energies of single $\mathrm{C}-\mathrm{H} \cdots \mathrm{O}(\mathrm{C})(\mathbf{b}), \mathrm{C}-\mathrm{H} \cdots \pi(\mathbf{d})$ and $\pi \cdots \pi(\mathbf{e}$ and $\mathbf{f})$ interactions in the gaseous phase estimated on this basis would be 7.3 (b), 22.3 (d), 22.9 (e) and $24.5(\mathbf{f}) \mathrm{kJ} \mathrm{mol}^{-1}$ [the latter two values can be ascribed to one of two $\pi \cdots \pi$ interactions occurring between inversely oriented $\mathrm{Cg} 3$ (benzene) and $\mathrm{Cg} 2$ (2H-pyran-2-one) (e) and $\mathrm{Cg} 4$ (benzene) and $\mathrm{Cg} 2$ (2H-pyran-2-one) (f) rings in pairs of cations of 1 (Fig. 9)]. With these energy values, the abovementioned local interactions between ions contribute appreciably to their mutual orientation and stabilization of the crystal lattice.

Crystals of 1 should occur as a result of interactions lowering Gibbs free energy. In water, propan-2-ol and acetonitrile all the types of interactions considered, even between oppositely charged ions, bring about an increase in $\Delta G$ (Table 4). Only in diethyl ether do interactions between oppositely charged ions (represented by a and $\mathbf{c}$ ) cause $\Delta G$ to decrease. In the presence of this solvent, therefore, conditions appear that are favourable to the precipitation of $\mathbf{1}$, which are made use of during the synthesis of the compound. As far as repulsive interactions between equally charged cations of $\mathbf{1}$ are concerned, they generally become weaker in various liquid phases (Table 4). As mentioned in the experimental section, crystals of the compound for X-ray investigations were grown from a propan-2-ol/acetonitrile $=4 / 1$ mixture. It is not possible to carry out PCM calculations for such a phase. Nevertheless, those that were performed show that a liquid phase containing acetonitrile and propan-2-ol, weakening repulsive interactions between equally charged ions and maintaining such interactions between oppositely charged ions at a relatively low level, is a good experimental choice of a crystallization solvent.
Crystals of $\mathbf{1}$ are composed of formally singly charged molecular ions, namely organic cations (Fig. 1) and inorganic $\mathrm{ClO}_{4}{ }^{-}$anions. Such a charge distribution between ions roughly occurs in cation-anion pairs (Table $5 \mathrm{~S}$ in the Supplementary data), which endorses the assumptions underlying the crystal lattice energy calculations. The crystal lattice energy (enthalpy), reflecting the energy released upon the formation of a solid phase from isolated gaseous ions, is predicted to be $-590.8(-595.8) \mathrm{kJ} \mathrm{mol}^{-1}$. A major contribution to this value amounting to $-395.9 \mathrm{~kJ} \mathrm{~mol}^{-1}$ comes from Coulombic interactions. The combined contribution from dispersive and repulsive interactions is lower $\left(-194.9 \mathrm{~kJ} \mathrm{~mol}^{-1}\right)$. The crystal lattice energy representing global interactions in the solid phase can be compared with the energies of specific local interactions between the ions listed in Table 4. This comparison shows that the energy released following the formation of 1 mol of cation-anion pairs makes up more than half of the crystal lattice energy. Individual specific interactions contribute just a few per cent to the crystal lattice energy. Nevertheless, they do influence the mutual orientation of ions and together contribute to the stabilization of the solid phase.

The magnitude of the negative entropy term destabilizing the crystal lattice is difficult to assess because the relevant thermodynamic data are lacking and there is no way of predicting them (for solid $\mathbf{1}$ ). In the formation of 1 mol of cation-anion pairs ( $\mathbf{a}$ in Table 4 ), $-T \Delta S$ is equal to $40.8 \mathrm{~kJ} \mathrm{~mol}^{-1}$, i.e. makes up only $13.6 \%$ of the latticestabilizing enthalpy term. For the formation of simple $\mathrm{NaCl}$ ionic crystals from gaseous ions, the entropy term (taken to be $-T \Delta S$ ) makes up $8.7 \%$ of the crystal lattice enthalpy (on the basis of data reported in NIST [60] ). Assuming that the contribution to the entropy of crystalline $\mathbf{1}$ comes only from molecular vibrations of ions (identical to those in the gaseous phase) and not from lattice (neglected) and molecular vibrations, and taking the predicted (MP2 level) entropies of the ions making up the compound, the value of $-T \Delta S$ would be $173.9 \mathrm{~kJ} \mathrm{~mol}^{-1}$, i.e. would reach at most $29.2 \%$ of the above-mentioned crystal lattice enthalpy. This means that entropy term destabilizing the crystal lattice of $\mathbf{1}$ does not predominate at room temperature.

\section{Molecular packing of 1 in the context of global and local interactions in the crystal lattice}

The main forces leading to the formation of crystalline ionic substances such as $\mathbf{1}$ are electrostatic interactions between ions. These long-range interactions are globally attractive because oppositely charged ions are located closer to one another than equally charged ones, which gives rise to the strong energy decrease expressed by the Coulombic contribution to the crystal lattice energy. 


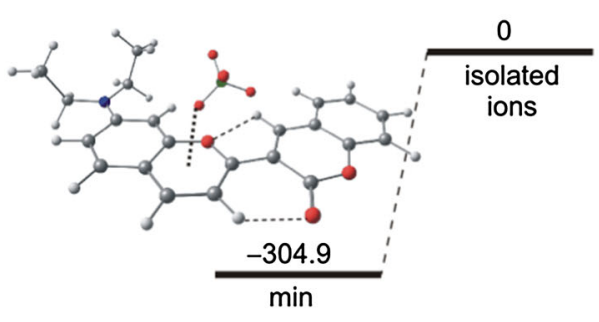

a
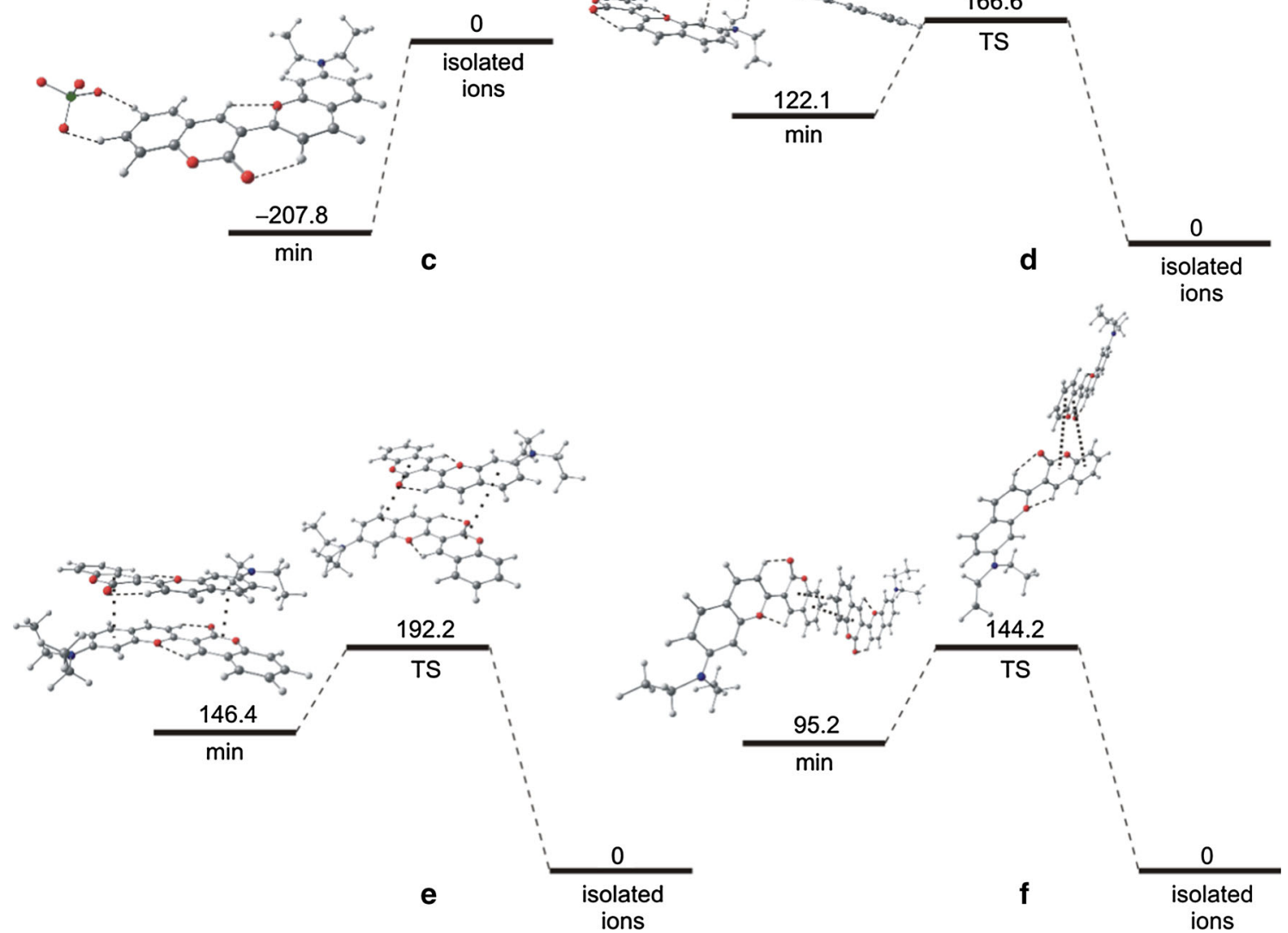

Fig. 9 Optimized structures (DFT/6-31G** level) and relative energies (in $\mathrm{kJ} \mathrm{mol}^{-1}$ ) representing stationary points [minima (min) and transition states (TS)] following the formation of assemblies of

Crystals are, however, formed under certain experimental conditions, usually after dissolution of the compound in an appropriately selected liquid phase. In such a phase, interactions between oppositely charged ions leading to the formation of ion pairs should be attractive; otherwise,
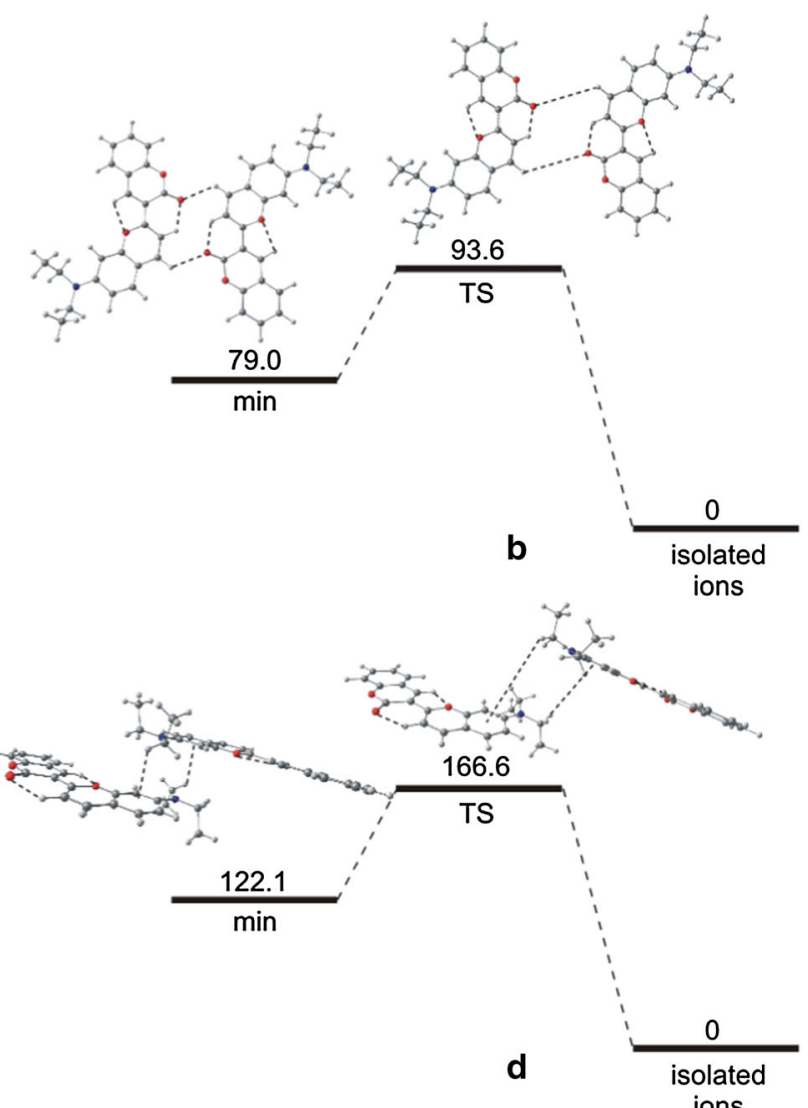

ions

oppositely (ion pairs, a and c) or equally (dimers, b, d, e and f) charged ions in the gaseous phase (for further information see Table 4)

the ions would not approach one another. In the case of $\mathbf{1}$, crystals were grown from a 4/1 propan-2-ol/acetonitrile mixture. It is demonstrated that the formation of cationanion pairs in propan-2-ol is possible since the Gibbs free energy of the process is equal to $2.8 \mathrm{~kJ} \mathrm{~mol}^{-1}$ (Table 4), 
Table 4 Computationally predicted thermodynamic data (in $\mathrm{kJ} \mathrm{mol}^{-1}$ ) for the formation of assemblies of oppositely (ion pairs, $\mathbf{a}$ and $\mathbf{c}$ ) or equally (dimers, b, d, e and f) charged ions in the gaseous phase or liquid environments

\begin{tabular}{|c|c|c|c|c|c|c|c|c|}
\hline \multirow[t]{3}{*}{ Ion assembly (Fig. 9) } & \multicolumn{8}{|c|}{ Gaseous phase } \\
\hline & \multicolumn{2}{|l|}{$\overline{\Delta E}$} & \multicolumn{3}{|c|}{$\Delta H$} & \multicolumn{3}{|l|}{$\Delta G$} \\
\hline & $\min$ & TS & \multicolumn{2}{|c|}{$\min$} & TS & \multicolumn{2}{|l|}{$\min$} & TS \\
\hline $\mathbf{a}$ & \multicolumn{2}{|l|}{$\begin{array}{l}-304.9 \\
(-335.0)\end{array}$} & \multicolumn{2}{|c|}{$\begin{array}{l}-299.6 \\
(-329.7)\end{array}$} & & \multicolumn{2}{|c|}{$\begin{array}{l}-258.8 \\
(-288.9)\end{array}$} & \\
\hline b & $\begin{array}{l}79.0 \\
(70.0)\end{array}$ & $\begin{array}{l}93.6 \\
(84.5)\end{array}$ & \multicolumn{2}{|c|}{$\begin{array}{l}84.5 \\
(75.5)\end{array}$} & $\begin{array}{l}96.6 \\
(87.4)\end{array}$ & \multicolumn{2}{|c|}{$\begin{array}{l}122.5 \\
(113.5)\end{array}$} & $\begin{array}{l}136.7 \\
(127.5)\end{array}$ \\
\hline c & $\begin{array}{l}-207.8 \\
(-221.9)\end{array}$ & & \multicolumn{2}{|c|}{$\begin{array}{l}-203.8 \\
(-218.0)\end{array}$} & & \multicolumn{2}{|c|}{$\begin{array}{l}-171.2 \\
(-185.3)\end{array}$} & \\
\hline d & $\begin{array}{l}122.1 \\
(121.5)\end{array}$ & $\begin{array}{l}166.6 \\
(159.2)\end{array}$ & \multicolumn{2}{|c|}{$\begin{array}{l}121.2 \\
(120.6)\end{array}$} & $\begin{array}{l}170.9 \\
(163.5)\end{array}$ & \multicolumn{2}{|c|}{$\begin{array}{l}162.7 \\
(162.1)\end{array}$} & $\begin{array}{l}208.6 \\
(201.2)\end{array}$ \\
\hline $\mathbf{e}$ & $\begin{array}{l}146.4 \\
(137.9)\end{array}$ & $\begin{array}{l}192.2 \\
(168.2)\end{array}$ & \multicolumn{2}{|c|}{$\begin{array}{l}146.3 \\
(137.8)\end{array}$} & $\begin{array}{l}194.9 \\
(171.0)\end{array}$ & \multicolumn{2}{|c|}{$\begin{array}{l}199.2 \\
(190.7)\end{array}$} & $\begin{array}{l}253.8 \\
(229.8)\end{array}$ \\
\hline f & $\begin{array}{l}95.2 ; 88.3 \\
(88.6 ; 74.9)\end{array}$ & $\begin{array}{l}144.2 \\
(127.2)\end{array}$ & \multicolumn{2}{|c|}{$\begin{array}{l}98.3 ; 91.1 \\
(91.8 ; 77.8)\end{array}$} & $\begin{array}{l}146.6 \\
(129.7)\end{array}$ & \multicolumn{2}{|c|}{$\begin{array}{l}144.4 ; 141.4 \\
(137.8 ; 128.0)\end{array}$} & $\begin{array}{l}197.1 \\
(180.2)\end{array}$ \\
\hline \multirow[t]{3}{*}{ Ion assembly (Fig. 9) } & \multicolumn{8}{|c|}{ Liquid environment $(\Delta G)$} \\
\hline & \multicolumn{2}{|c|}{ diethyl ether } & \multicolumn{2}{|c|}{ acetonitrile } & \multicolumn{2}{|c|}{ propan-2-ol } & \multicolumn{2}{|l|}{ water } \\
\hline & $\min$ & $\mathrm{TS}$ & $\min$ & $\mathrm{TS}$ & $\min$ & $\mathrm{TS}$ & $\min$ & TS \\
\hline $\mathbf{a}$ & -59.2 & 1.2 & 11.3 & 26.8 & 2.8 & 18.6 & 12.7 & 25.6 \\
\hline b & 34.1 & 47.3 & 38.8 & 54.2 & 35.2 & 60.4 & 33.1 & 59.6 \\
\hline c & -23.7 & 2.3 & 22.3 & 40.3 & 14.7 & 28.7 & 21.6 & 40.1 \\
\hline d & 57.0 & 96.8 & 33.6 & 62.7 & 46.6 & 59.9 & 39.3 & 54.8 \\
\hline $\mathbf{e}$ & 64.8 & 98.5 & 53.1 & 84.0 & 54.4 & 83.0 & 55.2 & 75.9 \\
\hline $\mathbf{f}$ & 48.9 & 59.5 & 50.3 & 60.6 & 49.6 & 58.9 & 43.4 & 53.9 \\
\hline
\end{tabular}

Differences of energy $(\Delta E)$, enthalpy $(\Delta H)$ and Gibbs free energy $(\Delta G)$ corresponding to stationary points [minima ( $\mathrm{min}$ ) or transition states (TS)] predicted at the DFT/6-31G** and (in the case of f) DFT-D/6$31 \mathrm{G}^{* *}$ (second value) (gaseous phase; in parentheses, values without inclusion of base superposition error) or DFT(PCM)/6-31G** levels which corresponds to an equilibrium constant of 0.32 . Thus, a conspicuous number of such pairs should exist in the equilibrium state. If one assumes that cation-anion pair formation is the first step in the crystallization of $\mathbf{1}$, then the next steps would be the growth of the crystal by the incorporation of successive ion pairs. Crystal growth is followed by a decrease in energy since electrostatic interactions between ions are much stronger in the absence of a solvent (Table 4). The mutual arrangement of ions in a growing crystal lattice depends to some extent on non-specific dispersive and repulsive interactions (included in the calculated crystal lattice energy) but predominantly on identified specific local $\mathrm{C}-\mathrm{H} \cdots \mathrm{O}(\mathrm{C})$, C$\mathrm{H} \cdots \pi$ and $\pi \cdots \pi$ interactions. Intramolecular $\mathrm{C}-$ $\mathrm{H} \cdots \mathrm{O}(\mathrm{C})$ interactions stabilize the almost planar structure of the cation core, and this may facilitate other interactions, e.g. of the $\pi \cdots \pi$ type. On the other hand, intermolecular $\mathrm{C}-\mathrm{H} \cdots \mathrm{O}(\mathrm{C})$ and $\mathrm{C}-\mathrm{H} \cdots \pi$ interactions link cations of adjacent ion pairs and contribute to the stabilization of the whole crystal lattice.

\section{Spectral features of 1 in solid phase and solutions}

Compounds containing chromenium or $2 \mathrm{H}$-chromen-2-one fragments in their structure efficiently absorb radiation from the visible region and emit it in this region [2-8]. Absorption of compound $\mathbf{1}$, in which the two above-mentioned fragments are combined, is red shifted (Fig. 7S in the Supplementary data), while its emission is very week. Furthermore, the spectral characteristics of $\mathbf{1}$ are markedly influenced by acidity/basicity as a result of the reversible protonation/deprotonation of the amino $\mathrm{N}$ atom or the nonreversible hydroxylation of the pyranium ring, most probably in the para position with respect to the endocyclic $\mathrm{O}$ atom (Fig. 7S in the Supplementary data), and the structural (Fig. 8S in the Supplementary data) and electron population changes accompanying these latter processes (Fig. 9S in the Supplementary data). The behaviour of compound $\mathbf{1}$ (its cation) outlined above makes it a promising spectral indicator of acidity or electrophilicity/ nucleophilicity of an environment [6]. 


\section{Conclusions}

The existence of various specific interactions/contacts between certain sites of molecular ions constituting the crystal lattice of $\mathbf{1}$ confirm results the quantum chemistry calculations.

It emerges from these calculations that the energy of two intramolecular H-bonding interactions in the cation of $\mathbf{1}$, which form $\mathrm{S}(5)$ and $\mathrm{S}(6) \mathrm{H}$-bond synthons (Table 1; Fig. 2), is $23.4 \mathrm{~kJ} \mathrm{~mol}^{-1}$. This implies that they make a pronounced contribution to the maintenance of its planarity.

The energies of a single specific intra- and intermolecular $\mathrm{C}-\mathrm{H} \cdots \mathrm{O}(\mathrm{C})$ contact, as well as of intermolecular $\mathrm{C}-\mathrm{H} \cdots \pi$ and $\pi \cdots \pi$ interactions, amounting to 9.5 (on average), 22.3 and 23.7 (on average), respectively, are significantly higher than those of the non-specific dispersive interactions (energy of the order of a few $\mathrm{kJ} \mathrm{mol}^{-1}$ ) [10]. This provides sufficient motivation to include them in crystal structure analysis, crystal engineering and the design of new crystalline materials.

The main contribution to the stabilization of the crystal lattice of $\mathbf{1}$, which comes from long-range electrostatic interaction between ions, overlaps the common but less pronounced short-range non-specific dispersive and repulsive interactions between these entities.

Various specific local interactions play an important role in the mutual orientation of ions and their placement in the crystalline solid phase. The destabilizing crystal lattice entropy term is not dominant at room temperature.

Thermodynamic analysis of interactions between oppositely and equally charged ions explains their behaviour in various liquid environments and forms the basis for modelling conditions favourable to the crystallization of $\mathbf{1}$.

The absorption features of $\mathbf{1}$ are promising as regards its application as an indicator of the acidity or electrophilicity/ nucleophilicity of a liquid environment.

\section{Supplementary data}

Supplementary data available: CCDC 916451 [crystallographic data (CIF) for compound 1] and details concerning: identification of the compound, X-ray measurements, structural features, intermolecular interactions and electronic absorption phenomena.

Acknowledgments This study was financed by the State Funds for Scientific Research (Grants: DS/530-8220-D184-13, BW/538-8220B004-13 and BW/538-8220-B331-14). M. W. acknowledges financial support from the European Social Fund within the Project "Educators for the elite-integrated training programme for Ph.D. students, Postdocs and Professors as academic teachers at the University of Gdańsk", and the Human Capital Operational Programme Action
4.1.1, "Improving the quality on offer at tertiary educational institutions". B. Z. acknowledges financial support from the European Social Fund within the project "The development programme of the University of Gdansk in areas of Europe 2020 (UG 2020)". This publication reflects the views only of the authors: the sponsor cannot be held responsible for any use which may be made of the information contained herein. We are greatly indebted to Professors I. Anusiewicz and P. Skurski (University of Gdańsk) for granting access to their computing machines. The calculations were also carried out on computers of the Tri-City Academic Network Computer Centre in Gdańsk (TASK) and the Wroclaw Centre for Networking and Supercomputing (WCSS).

Open Access This article is distributed under the terms of the Creative Commons Attribution 4.0 International License (http:// creativecommons.org/licenses/by/4.0/), which permits unrestricted use, distribution, and reproduction in any medium, provided you give appropriate credit to the original author(s) and the source, provide a link to the Creative Commons license, and indicate if changes were made.

\section{References}

1. O'Kennedy R, Thornes R (1997) Coumarins: biology, applications and mode of action. Wiley, Chichester

2. Kitamura N, Fukagawa T, Kohtani S, Kitoch S, Nakagaki R (2007) Synthesis, absorption, and fluorescence properties and crystal structures of 7-aminocoumarin derivatives. J Photochem Photobiol A 188:378-386

3. Al-Kindy SMZ, Al-Sharji N, Al-Harasi AF, Suliman FO, AlLawati HJ, Schulman S (2012) Synthesis and spectroscopic study of 2,7-diethylamino-2-oxo-2H-chromen-3-yl benzothiazole-6sulfonyl chlorides and its derivatives. Arab J Chem. doi:10.1016/ j.arabjc.2012.06.015

4. Gao F, Li HR, Yang YY (2000) Influence of the molecular structure and medium on the absorption and emission character of ketocoumarin derivatives and probability of as fluorescence probes. Dyes Pigments 47:231-238

5. Sheng JR, Feng F, Qiang Y, Liang FG, Sen L, Wei FH (2008) A coumarin-derived fluorescence chemosensors selective for copper(II). Anal Lett 41:2203-2213

6. Roshal AD, Minaev DY, Koval VL, Novikov AI (1998) Luminescent properties of 2-phenylbenzopyrylium salts. Opt Spectrosc 85:705-710

7. Signore G, Nifosi R, Albertazzi L, Storti B, Bizzarri R (2010) Polarity-sensitive coumarins tailored to live cell imaging. J Am Chem Soc 132:1276-1288

8. Mertens MD, Gütschow M (2013) Synthesis and evaluation of two coumarin-type derivatization reagents for fluorescence detection of chiral amines and chiral carboxylic acids. Chirality 25:957-964

9. Novoa JJ, Mota F, D’Oria E (2006) In: Grabowski S (ed) Hydrogen bonding-new insights. Springer, Amsterdam

10. Gao HY, Zhao XR, Wang H, Pang X, Jin WJ (2012) Phosphorescent cocrystals assembled by 1,4-diiodotetrafluorobenzene and fluorene and its heterocyclic analogues based on $\mathrm{C}-\mathrm{I} \cdots \pi$ halogen bonding. Cryst Growth Des 12:4377-4387

11. Zhu Q, Wang H, Zhao XR, Jin WJ (2014) The phosphorescent behaviors of 9-bromo- and 9-iodophenanthrene in crystals modulated by $\pi-\pi$ interactions, $\mathrm{C}-\mathrm{H} \cdots \pi$ hydrogen bond and $\mathrm{C}-$ I $\cdots \pi$ halogen bond. J Photochem Photobiol A Chem 274:98-107

12. Podeszwa R, Szalewicz K (2008) Physical origins of interactions in dimers of polycyclic aromatic hydrocarbons. Phys Chem Chem Phys 10:2735-2746 
13. Kelly B, Sánchez-Sanz G, Blanco F, Rozas I (2012) Cation- $\pi v s$. $\pi-\pi$ interactions: complexes of 2-pyridinylguanidinium derivatives and aromatic systems. Comp Theor Chem 998:64-73

14. Corrêa RS, dos Santos MH, Nagem TJ, Ellena J (2012) Hostguest interactions between xanthones and water: the role of $\mathrm{O}-$ $\mathrm{HO}, \mathrm{C}-\mathrm{HO}$, and $\pi \cdots \pi$ contacts in the channel- and cage-type frameworks. Struct Chem 23:1809-1818

15. Czerney P, Graneß G, Birckner E, Vollmer F, Rettig W (1995) Molecular engineering of cyanine-type fluorescent and laser dyes. J Photochem Photobiol A Chem 89:31-36

16. Farrugia LJ (2012) WinGX and ORTEP for windows: an update. J Appl Cryst 45:849-854

17. Spek AL (2009) Structure validation in chemical crystallography. Acta Cryst D65:148-155

18. Wolff SK, Grimwood DJ, McKinnon JJ, Turner MJ, Jayatilaka D, Spackman MA (2012) CrystalExplorer (Version 3.1), University of Western Australia. http://hirsfeldsurface.net

19. Frisch MJ, Trucks GW, Schlegel HB, Scuseria GE, Robb MA, Cheeseman JR, Scalmani G, Barone V, Mennucci B, Petersson GA, Nakatsuji H, Caricato M, Li X, Hratchian HP, Izmaylov AF, Bloino J, Zheng G, Sonnenberg JL, Hada M, Ehara M, Toyota K, Fukuda R, Hasegawa J, Ishida M, Nakajima T, Honda Y, Kitao O, Nakai H, Vreven T, Montgomery Jr. JA, Peralta JE, Ogliaro F, Bearpark M, Heyd JJ, Brothers E, Kudin KN, Staroverov VN, Keith T, Kobayashi R, Normand J, Raghavachari K, Rendell A, Burant JC, Iyengar SS, Tomasi J, Cossi M, Rega N, Millam JM, Klene M, Knox JE, Cross JB, Bakken V, Adamo C, Jaramillo J, Gomperts R, Stratmann RE, Yazyev O, Austin AJ, Cammi R, Pomelli C, Ochterski JW, Martin RL, Morokuma K, Zakrzewski VG, Voth GA, Salvador P, Dannenberg JJ, Dapprich S, Daniels AD, Farkas O, Foresman JB, Ortiz JV, Cioslowski J, Fox DJ (2010) Gaussian 09, Revision B.01, Gaussian, Inc., Wallingford CT

20. Labanowski JK, Andzelm JW (1991) Density functional methods in chemistry. Springer, New York

21. Grimme S (2006) Semiempirical GGA-type density functional constructed with a long-range dispersion correction. J Comput Chem 27:1787-1799

22. Scalmani G, Frisch MJ, Mennucci B, Tomasi J, Cammi R, Barone V (2006) Geometries and properties of excited states in the gas phase and in solution: theory and application of a time-dependent density functional theory polarizable continuum model. J Chem Phys 124:094107-1-094107-15

23. Becke AD (1993) A new mixing of Hartree-Fock and local density-functional theories. J Chem Phys 98:1372-1377

24. Becke AD (1993) Density-functional thermochemistry. III. The role of exact exchange. J Chem Phys 98:5648-5652

25. Lee C, Yang W, Parr RG (1988) Development of the ColleSalvetti correlation-energy formula into a functional of the electron density. Phys Rev B 37:785-789

26. Schlegel HB (1994) Modern electronic structure theory: geometry optimization on potential energy surfaces. World Scientific Publishing, Singapore

27. Hehre WJ, Radom L, PvR Schleyer, Pople JA (1986) Ab initio molecular orbital theory. Wiley, New York

28. Møller C, Plesset MS (1934) Note on an approximation treatment for many-electron systems. Phys Rev 46:618-622

29. Francl MM, Pietro WJ, Hehre WJ, Binkley JS, Gordon MS, DeFrees DJ, Pople JA (1982) Self-consistent molecular orbital methods. XXIII. A polarization-type basis set for second-row elements. J Chem Phys 77:3654-3665

30. Hariharan PC, Pople JA (1973) The influence of polarization functions on molecular orbital hydrogenation energies. Theor Chim Acta 28:213-222

31. Tomasi J, Persico M (1994) Molecular interactions in solution: an overview of methods based on continuous distributions of the solvent. Chem Rev 94:2027-2094
32. Barone V, Cossi M, Mennucci B, Tomasi J (1997) A new definition of cavities for the computation of solvation free energies by the polarizable continuum model. J Chem Phys 107:3210-3221

33. Dewar MJS, Ford GP (1977) Ground states of molecules. 44 MINDO/3 calculations of absolute heat capacities and entropies of molecules without internal rotations. J Am Chem Soc 99:7822-7829

34. Ditchfield R (1974) Self-consistent perturbation theory of diamagnetism. I. A gauge-invariant LCAO method for NMR chemical shifts. Mol Phys 27:789-807

35. Wolinski K, Hinton JF, Pulay P (1990) Efficient implementation of the gauge-independent atomic orbital method for NMR chemical shift calculations. J Am Chem Soc 112:8251-8260

36. Gauss J (1993) Effects of electron correlation in the calculation of nuclear magnetic resonance chemical shifts. J Chem Phys 99:3629-3643

37. Gale JD (1997) GULP: a computer program for the symmetryadapted simulation of solids. J Chem Soc Faraday Trans 93:629-637

38. Besler BH, Merz KM, Kollman PA (1990) Atomic charges derived from semiempirical methods. J Comput Chem 11:431-439

39. Zhao Y, Truhlar DG (2008) The M06 suite of density functionals for main group thermochemistry, thermochemical kinetics, noncovalent interactions, excited states, and transition elements: two new functionals and systematic testing of four M06-class functionals and 12 other functionals. Theor Chem Acc 120:215-241

40. Zhao Y, Truhlar DG (2008) Density functionals with broad applicability in chemistry. Acc Chem Res 41:157-167

41. Ditchfield R, Hehre WJ, Pople JA (1971) Self-consistent molecular-orbital methods. IX. An extended Gaussian-type basis for molecular-orbital studies of organic molecules. J Chem Phys 54:724-728

42. Filippini G, Gavezzotti A (1993) Empirical intermolecular potentials for organic crystals: the '6-exp' approximation revisited. Acta Crystallogr Sect B 49:868-880

43. Mayo SL, Olafson BD, Goddard WA (1990) DREIDING: a generic force field for molecular simulations. J Phys Chem 94:8897-8909

44. Roque A, Lodeiro C, Pina F, Maestri M, Ballardini R, Balzani V (2002) Photochromic properties of 3-methyl-substituted flavylium salts. Eur J Org Chem 2002:2699-2709

45. Moncada MC, Moura S, Melo MJ, Roque A, Lodeiro C, Pina F (2003) Complexation of aluminum(III) by anthocyanins and synthetic flavylium salts: a source for blue and purple color. Inorg Chim Acta 365:51-61

46. Toräng J, Vanderheiden S, Nieger M, Bräse S (2007) Synthesis of 3 -alkylcoumarins from salicylaldehydes and $\alpha, \beta$-unsaturated aldehydes utilizing nucleophilic carbenes: a new umpoled domino reaction. Eur J Org Chem 2007:943-952

47. Nair V, Sinu CR, Rejithamol R, Lakshmi KCS, Suresh E (2011) A novel NHC-catalyzed transformation of $2 \mathrm{H}$-chromene-3-carboxaldehydes to 3-methyl-2H-chromen-2-ones. Org Biomol Chem 9:5511-5514

48. Roshal AD, Sikorski A, Baumer VN, Novikov AI, Blazejowski J (2007) Two polymorphs of 2-(4-chloro-phenyl)-4-methylchromenium perchlorate. Acta Cryst Sect C 63:0626-o630

49. Sun Y-X (2005) [4-Bromo-2-(pyridin-2-ylmethyliminomethyl) phenolato](methanol)copper(II) perchlorate. Acta Crystallogr Sect E 61:m338-m340

50. Athimoolam S, Rajaram RK (2006) Thiaminium chloride perchlorate. Acta Crystallogr Sect E 62:o202-o204

51. Hirshfeld FL (1977) Bonded-atom fragments for describing molecular charge densities. Theor Chim Acta 44:129-138

52. McKinnon JJ, Spackman MA, Mitchell AS (2004) Novel tools for visualizing and exploring intermolecular interactions in molecular crystals. Acta Crystallogr Sect B 60:627-668 
53. Rohl AL, Moret M, Kaminsky W, Claborn K, McKinnon JJ, Kahr B (2008) Hirshfeld surfaces identify inadequacies in computations of intermolecular interactions in crystals: pentamorphic 1,8dihydroxyanthraquinone. Cryst Growth Des 8:4517-4525

54. Rozycka-Sokolowska E, Marciniak B, Kosik S, Dondela B, Bak Z (2015) Two isostructural halogen derivatives of 9-ethylcarbazole: crystal structure, Hirshfeld surface analysis, and structural comparison with other simple analogs. Struct Chem. doi:10.1007/ s11224-014-0538-8

55. Clausen HF, Chevallier MS, Spackman MA, Iversen BB (2010) Three new co-crystals of hydroquinone: crystal structures and Hirshfeld surface analysis of intermolecular interactions. New $\mathbf{J}$ Chem 34:193-199

56. Lin L, Fei Z, Meng X-G, Cao L-P, Cai Q, Sun R-Q, Wu A-X (2013) Organic hydrogen-bonded assembly of asymmetric phenol amide molecules. Struct Chem 24:1419-1428
57. Rybarczyk-Pirek AJ, Łukomska M, Ejsmont K, Jasiński M, Palusiak M (2014) Temperature-dependent polymorphism of $\mathrm{N}$-(4-fluorophenyl)-1,5-dimethyl-1H-imidazole-4-carboxamide 3-oxide: experimental and theoretical studies on intermolecular interactions in the crystal state. Struct Chem 25:979-989

58. Grimme S (2004) Accurate description of van der Waals complexes by density functional theory including empirical corrections. J Comput Chem 25:1463-1473

59. Riley KE, Pitoňák M, Černý J, Hobza P (2010) On the structure and geometry of biomolecular binding motifs (hydrogen-bonding, stacking, $\mathrm{X}-\mathrm{H} \cdots \pi)$ : WFT and DFT calculations. J Chem Theory Comput 6:66-80

60. NIST Standard Reference Database (2014). http://webbook.nist. gov. Accessed 21 Nov 2014 